\title{
Hybrid III ATD in Inverted Impacts: Influence of Impact Angle on Neck Injury Risk Assessment
}

\author{
B. Fréchède ${ }^{1}$, A. McIntosh ${ }^{1}$, R.Grzebieta ${ }^{2}$, M. Bambach ${ }^{3}$ \\ ${ }^{1}$ School of Risk and Safety Sciences, The University of New South Wales, Sydney, NSW 2052, Australia; \\ ${ }^{2}$ NSW Injury Risk Management Research Centre, The University of New South Wales, Sydney, NSW, Australia; \\ ${ }^{3}$ Department of Civil Engineering, Monash University, Melbourne, VIC, Australia
}

\begin{abstract}
The purpose of this paper is to present a protocol of inverted drop-tests using a $50^{\text {th }}$ percentile Hybrid III Anthropomorphic Test Device (ATD) and investigate the influence of angle and velocity at impact on neck injury risk assessment. The tests were based on existing cadaveric experimental protocols for inverted seated positions. In this study selected ATD impact orientations were also assessed in both the sagittal and coronal planes. Twenty-six tests were performed at impact velocities from $1.4 \mathrm{~m} . \mathrm{s}^{-1}$ to $3.1 \mathrm{~m} . \mathrm{s}^{-1}$. The drop tests confirmed previously described behaviour of the ATD in axial loading of its head/neck/thorax complex. They also showed a significant influence of the initial impact angle on neck injury criteria currently used by researchers in rollover crashworthiness tests. At 1.4 m.s ${ }^{-1}$, the peak upper neck axial force of $4350 \mathrm{~N}$ was reduced by an average $1760 \mathrm{~N} \pm 80 \mathrm{~N}$ for configurations with 30 degrees initial impact angle in any plane, compared to a reference inverted vertical configuration. The $\mathrm{N}_{\mathrm{ij}}$ was also significantly influenced. For a given impact velocity, an out-of-both-planes initial configuration resulted in the highest combined outputs. Based on these results, similar dynamic conditions (intrusion velocity, impact duration) may result in significantly different loadings of the Hybrid III neck.
\end{abstract}

Keywords - Axial impact, Cervical spine injury, Injury criteria, Rollover

\section{INTRODUCTION}

Biomechanical research on impact injury mechanisms, human tolerance, dynamic responses and anthropomorphic test devices (ATD) is fundamental to the design and performance specifications for occupant safety systems and crashworthy vehicles. This paper focuses on ATD use in the assessment of rollover vehicle crashworthiness. Vehicle rollover crashes remain a major concern internationally because of the associated head and neck injury risks, and resultant impairment to both the ejected and contained occupant ${ }^{6,14}$.

The Hybrid III ATD has been used in a range of rollover crashworthiness tests by researchers to assess neck injury risks to contained occupants, even though it was designed for frontal impacts $2,3,8,9,11,13,20,28,32,35$. Most of these tests have used the ATD's upper neck axial force as an indicator of neck injury risk. Research on neck biomechanics has shown that compressive failure of the neck is dependent on its loading mode ${ }^{21}$ and that it will be exacerbated by out-of-theplane components ${ }^{26,38}$. Complex loading modes are present in a rollover crash due to the combination of roof structure failure, lateral vehicle velocity component prior to rollover and occupant kinematics ${ }^{6,28}$. Although the Hybrid III's behaviour has been evaluated in a range of axial loading conditions ${ }^{5}, 10,17,18,23,27,29,32-34,39$, none has quantified the influence of the impact boundary conditions that arise in combination in rollovers: velocity, coronal plane and sagittal plane orientations.

The aims of the study were to: (1) develop an impact test representing an inverted occupant in a rollover crash suitable for assessing ATD performance; and (2) assess the biofidelic characteristics of the Hybrid III ATD systematically in inverted drop tests. The focus of the second aim was the ATD's sensitivity to impact velocity and impact angle, on the upper and lower neck load measures and $\mathrm{N}_{\mathrm{ij}}$.

\section{METHODS}

Drop-rig and ATD

A rigid steel frame was built to support and guide the ATD during the impact tests (Figure 1). The frame was guided in vertical translation by linear bearings/rails each mounted on a steel column. The dummy was fitted to a standard 5point safety harness and suspended on the frame by ropes in order to position and orient the ATD. The frame and ATD could be lifted and dropped simultaneously from a maximum effective drop-height of $1 \mathrm{~m}$. During the resulting free 
fall drop, the ATD maintained its initial orientation to impact a padded load plate/anvil on its head. The frame continued to drop without interfering with the ATD's impact event and was finally stopped by aluminium honeycomb. A calibrated male $50^{\text {th }}$ percentile Hybrid III ATD (Denton ATD, Inc.) was used. A pedestrian pelvis was mounted on the dummy to allow modifying the hip joint angle. All joint resistances were set at $1 \mathrm{~g}$.

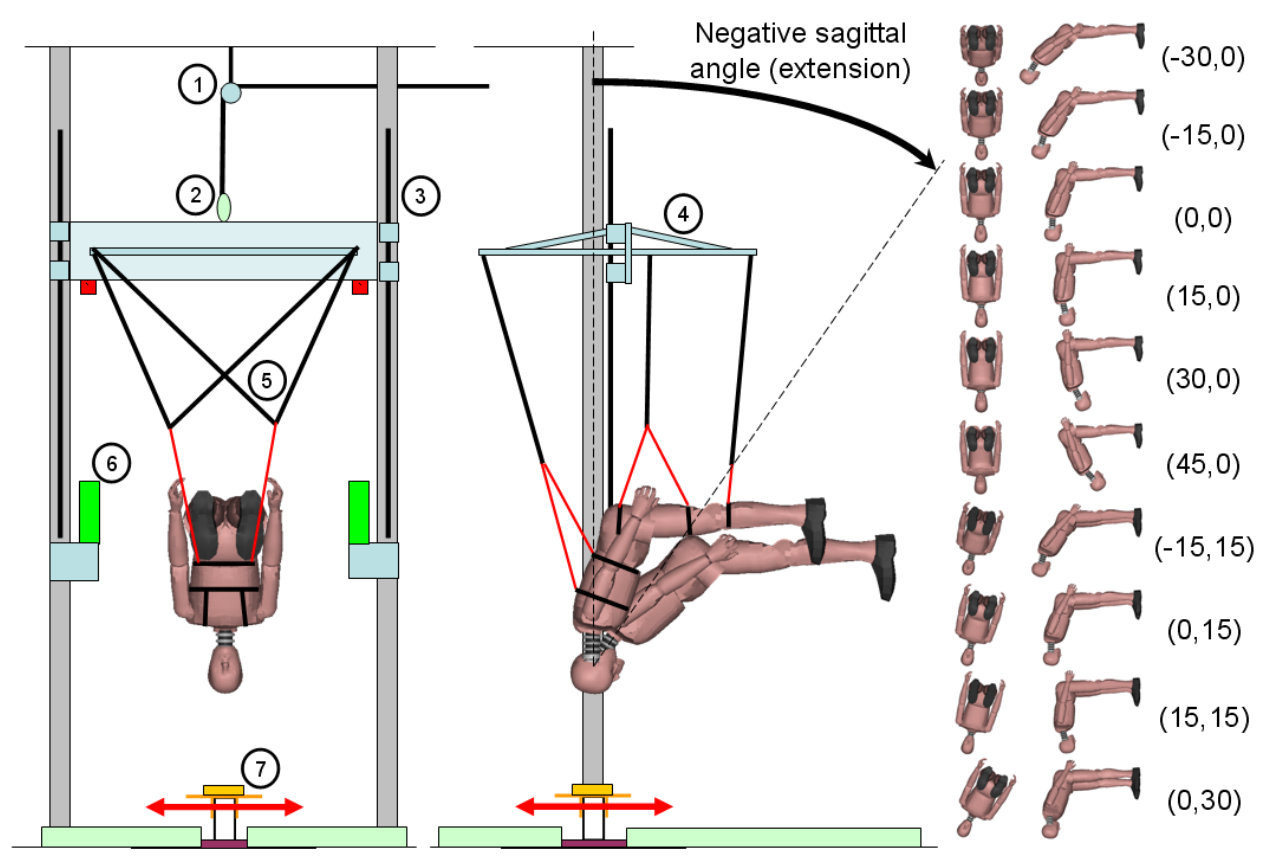

FIGURE 1. Schematic drawing of the drop-rig and configurations; Legend: 1. Lifting cable to pulley and winch, 2. Snapshackle quick-release, 3 . Linear guides mounted on universal columns, 4. Steel frame supporting ropes, 5 . Ropes attached to frame, connected to safety harness and dummy, 6. Shock absorption honeycomb material, 7. Anvil mounted Ensolite pad.

\section{Instrumentation and data acquisition}

SAE recommended practice J211/1 rev. Mar 95 instrumentation and data acquisition standards were applied. The Hybrid III ATD was instrumented according to Part 572E and included three linear accelerations at the ATD's head centre of gravity (CG), six upper neck forces and moments, six lower neck forces and moments and three linear accelerations in the thorax. Three 9331B (Kistler AG) force transducers were mounted between the padded load plate and the anvil. The anvil was fixed rigidly at the required location over a hardened concrete floor pit. The padding consisted of $2.54 \mathrm{~cm}$ (1 inch) thick Ensolite ${ }^{\circledR}$ foam (Gaska Tape (Australia) Pty Ltd). Signals were conditioned and acquired at 20,000 Hz using a TDASPro (Diversified Technical Systems, Inc.) and later resampled at 10,000 Hz.

Depending on the test series, one or two high-speed cameras (VisionResearch, Inc. - Phantom v4.0/v4.1/v4.3, 512x512 pixels at $1000 \mathrm{fps}$ ) recorded the impacts in the coronal and/or sagittal plane of the dummy. Both cameras and data acquisition were triggered simultaneously by a photoelectric sensor.

Upper neck moments were corrected according to Part 572E and the $\mathrm{N}_{\mathrm{ij}}$ was calculated for each test. The $\mathrm{N}_{\mathrm{ij}(\mathrm{C} 7 / \mathrm{T} 1)}$ as proposed by Mertz et al. ${ }^{19}$ was calculated for the lower neck. Statistical treatment of the data was performed using the statistical software SPSS v15 (SPSS Inc.). Statistical significance for correlation between variables was assessed using Spearman's test and measured against the level $\alpha<0.01$.

\section{Test Protocol}

The ATD's neck was used as a reference for the orientation of the whole ATD. Angles were measured between the neck and the vertical using an inclinometer. The notation (flexion/extension angle, lateral angle) was used to describe a test configuration. The $(0,0)$ configuration corresponded to the reference condition where the ATD's neck was vertical. Other configurations are described in figure 1. In all tests, the ATD's arms were strapped to its thorax and the legs were strapped together at thigh and calf levels. In all tests but two, the legs were horizontal.

The test matrix is presented in table 1. Twenty-six tests were planned, at impact speeds between $1.4 \mathrm{~m} . \mathrm{s}^{-1}$ and $3.1 \mathrm{~m} . \mathrm{s}^{-1}$. The ATD was positioned to achieve the target impact speed by using a rule and a $10 \mathrm{~cm}$ foam block was used as a positioning device for the $1.4 \mathrm{~m} . \mathrm{s}^{-1}$ tests. The impact velocity range was selected to reflect realistic dynamic roof crush 


\section{Author Created Version}

Original source of publication: Annals of Biomedical Engineering 37(7), p. 1403-1414, 2009

DOI: 10.1007/s10439-009-9711-4

The original publication is available at www.springerlink.com:

http://www.springerlink.com/openurl.asp?genre=article\&id=doi:10.1007/s10439-009-9711-4

intrusion velocities in rollovers ${ }^{4,9}$ and be comparable with cadaver and volunteer tests, both for non-injury ${ }^{10,26}$ and injury cases ${ }^{16,26,37}$ up to $4.1 \mathrm{~m} . \mathrm{s}^{-1}$. Because of the ATD's lower neck load cells' limited safe operating range, the tests were restricted to a maximum velocity of $3.1 \mathrm{~m} . \mathrm{s}^{-1}$. PVC adhesive tape was taped on both the dummy's head and the foam pad to protect the pads from being damaged during the contact, and in an attempt to reduce both possible high friction and encapsulating effects of the foam on the head. Tests were also carried out without the tape as a comparison. After each test all data including videos were reviewed. Based on this first review, one test (Test $3 b$ ) was discarded because the pad had detached from the load plate during the impact. A full re-calibration of the dummy was performed after tests 5 and 15.

TABLE 1. Test matrix.

\begin{tabular}{|c|c|c|c|c|c|c|}
\hline \multirow{3}{*}{$\begin{array}{l}\text { Lateral } \\
\text { Flex/Ext. } \\
-30\end{array}$} & \multicolumn{3}{|c|}{ Bare Ensolite foam } & \multicolumn{3}{|c|}{ Ensolite + PVC adhesive tape } \\
\hline & 0 & 15 & 30 & 0 & 15 & 30 \\
\hline & $12^{*}$ & & & $13,13 b$ & & \\
\hline-15 & 9 & & & $22\left(3.1 \mathrm{~m} . \mathrm{s}^{-1}\right)$ & 18 & \\
\hline 0 & $1^{\dagger}, 6$ & 2 & $3,3 b$ & $\begin{array}{l}14\left(1.93 \mathrm{~m} . \mathrm{s}^{-1}\right) \\
15\left(2.62 \mathrm{~m} . \mathrm{s}^{-1}\right)\end{array}$ & 16 & $5\left(3.1 \mathrm{~m} . \mathrm{s}^{-1}\right)$ \\
\hline 15 & 8 & & & $19\left(2.62 \mathrm{~m} . \mathrm{s}^{-1}\right)$ & 17 & \\
\hline $\begin{array}{l}30 \\
45\end{array}$ & 11 & & & $20\left(2.62 \mathrm{~m} . \mathrm{s}^{-1}\right)$ & & \\
\hline $\begin{array}{l}{ }^{*} \text { Impact velocit } \\
{ }^{\dagger} \text { In test } 1 \text {, both } \\
{ }^{\ddagger} \text { In test } 21 \text {, due } \\
\text { angle of about } 1\end{array}$ & $\begin{array}{l}.4 \text { m.s } \\
\text { e posi } \\
\text { iffness } \\
\text { es up }\end{array}$ & $\begin{array}{l}\text { nles } \\
\text { led a } \\
\text { the } \\
\text { mea }\end{array}$ & $\begin{array}{l}\text { erwise } \\
\text { out } 25 \\
\text { imy, it } \\
\text { ed. }\end{array}$ & $\begin{array}{l}\text { ed } \\
\text { up from the hor } \\
\text { possible to kee }\end{array}$ & $\begin{array}{l}\text { ntal } \\
\text { e le }\end{array}$ & zontal. An \\
\hline
\end{tabular}

\section{RESULTS}

In total 26 tests were conducted of which 25 tests were assessed as valid. The actual orientations and impact speeds were compared with the target using high speed video and were observed to be very similar.

When assessed with available video footage, the impact angles were within $5^{\circ}$ of the target angle in all but five cases. In tests $6 \mathrm{~b}, 7,16$ and 20 the error were, respectively, $-6^{\circ},-7^{\circ},-5.5^{\circ}$ and $-7^{\circ}$ from the intended sagittal angle. In test 14 there was an error estimated to be $-13.5^{\circ}$. This resulted in the exclusion of test 14 from the analysis of impact angle. In the sagittal plane, and after exclusion of test 14 , the average error was $-2.3 \pm 3.3^{\circ}$ from the target angle. When initially in a straight or flexed configuration, the dummy had a tendency to move into extension (resp. $-3.0 \pm 2.5^{\circ}$ and $-3.7 \pm 3.5^{\circ}$ difference to target angle) during guided free-fall. The ATD's position was well maintained for configurations in extension ( $0.6 \pm 2.6^{\circ}$ difference to target angle). In its coronal plane, the dummy remained in its vertical target orientation $\left(0.9 \pm 1.5^{\circ}\right.$ difference to target angle). The ATD moved towards a vertical orientation when positioned in a lateral configuration ( $-1.7 \pm 2.0^{\circ}$ difference to target angle).

Sixteen tests were identified with good quality high speed videos and minimal parallax error. The actual impact velocity was calculated over the five frames prior to contact with the pad, by tracking known targets on the dummy's head. The average difference as a proportion of the actual to the target velocity was estimated at $3.0 \pm 2.5 \%$. For the $1.4 \mathrm{~m} . \mathrm{s}^{-1}$ tests (12 videos assessed), the coefficient of variation of the actual velocity was $3 \%$.

The main peak ATD outputs are presented in tables 2 and 3, and figure 2 presents the associated sign conventions. Repeatability was assessed by comparing tests 13 and 13b. Signal time-histories, including the head and thorax accelerations were identical in shape (see figure 3), and the average ratio of the difference between meaningful peak ATD neck outputs in tests 13 and $13 b$ (excluding low level or lateral outputs in that case) was $10.1 \pm 4.7 \%$.

Consistent orientation dependent ATD behaviour was observed. When the dummy was in a slight or moderate initial positive flexion orientation, i.e. configurations $(15,0)$ or $(30,0)$, the head was unable to 'escape' the path of the falling torso in the first phase of the impact, resulting in an initial s-shaped bending of the neck, where the upper neck was in extension and the lower neck in flexion (figure 4a). In the second phase, the movement of the head-neck-torso complex changed to a flexion bending mode of the neck until the shoulders reached ground level. This phase resulted in combined high flexion bending moments and high antero-posterior shear forces at the dummy's lower neck level. In the $(45,0)$ configuration, there appeared to be no initial s-shaped neck phase, although initial upper neck extension moments remained high. Configuration $(15,15)$ presented a behaviour that was similar to $(15,0)$ but significantly influenced by the added lateral angle, the head and neck being trapped in an out-of-the plane twisted motion (figure 4c). 


\section{Author Created Version}

Original source of publication: Annals of Biomedical Engineering 37(7), p. 1403-1414, 2009

DOI: 10.1007/s10439-009-9711-4

The original publication is available at www.springerlink.com:

http://www.springerlink.com/openurl.asp?genre=article\&id=doi:10.1007/s10439-009-9711-4

When the dummy was in the reference configuration $(0,0)$ or in an extension configuration $((-15,0)$ or $(-30,0))$, the neck remained relatively straight and the dummy rebounded (figure $4 \mathrm{~b})$. In the lateral orientation configurations $(0,15)$, $(0,30)$ or $(-15,15)$, a minor short duration lateral s-shape was observed, followed by a phase during which the head and neck rapidly extended back to neutral.

The possible influence of the contact characteristics was assessed by comparing all outputs from the $1.4 \mathrm{~m} . \mathrm{s}^{-1} \mathrm{impacts}$ performed with the PVC tape to those equivalent without the tape. For tests with an initial 30 degrees impact angle in any direction, results obtained when using the tape were slightly lower (Wilcoxon's paired signed rank test $\mathrm{p}=0.002$ ) than their bare-foam counterparts. Non significant differences were found for impact configurations with less initial angle.

Neck force maxima were strongly influenced by the initial orientation of the dummy and velocity. For example, peak upper neck axial forces (-Fz) as different as $1591 \mathrm{~N}$ and $4351 \mathrm{~N}$ were found for tests 21 and $6 \mathrm{~b}$, both $1.4 \mathrm{~m} . \mathrm{s}^{-1}$ impacts in respectively the $(45,0)$ and $(0,0)$ configurations. For the 25 tests, there was a significant correlation between same components of the force at upper and lower neck levels. High shear forces, both in the sagittal and coronal planes, were measured at both neck levels, which were consistent with the expected loads from the impact configurations.

Upper neck moment maxima were less consistent than the force maxima with regard to impact orientation. The upper neck flexion/extension moment maximum was sensitive to small changes in orientation around the reference configuration (figure 6a) and appeared therefore not to correlate with impact velocity in this case (see tests 6b/15 results). No correlation existed between upper and lower neck moment maxima (figure 6b).

When an initial s-shape occurred, an upper neck moment maximum was associated with a maximum at the lower neck counterpart, but of opposite sign. This was observed in both the sagittal and coronal planes. Regardless of the impact angle, lower neck extension moments were minimal for all configurations and impact velocities tested. Comparatively, high (> 110 N.m at 2.62 m.s s $^{-1}$ upper neck extension moments were reached in both $(15,0)$ and $(30,0)$ impact configurations during the s-shaped neck response phase. Lower neck flexion moments were consistently very high reaching at least $100 \mathrm{~N} . \mathrm{m}$ for the $(-30,0)$ configuration, and as high as $481 \mathrm{~N} . \mathrm{m}$ for the $(0,0)$ configuration at $2.62 \mathrm{~m} . \mathrm{s}^{-1}$. In terms of timing, upper neck moment maxima occurred during the first phase of the impact and were associated with the peak compressive forces. Peak lower neck moments generally occurred during the same first phase of the impact. High lower neck moments, of the same magnitude, were also recorded in the second phase, e.g. when the chin rotated toward the torso in configurations with more than 15 degrees of initial ATD flexion. There was a significant correlation between the $\mathrm{N}_{\mathrm{ij}}$ and $\mathrm{N}_{\mathrm{ij}}$ (C7-T1). However this was not the case when comparing the $\mathrm{N}_{\mathrm{CE}}$ or $\mathrm{N}_{\mathrm{CF}}$ separately between both neck levels. 
Author Created Version

Original source of publication: Annals of Biomedical Engineering 37(7), p. 1403-1414, 2009

DOI: $10.1007 / \mathrm{s} 10439-009-9711-4$

The original publication is available at www.springerlink.com: http://www.springerlink.com/openurl.asp?genre=article\&id=doi:10.1007/s10439-009$\underline{9711-4}$

TABLE 2. Main peak results.

\begin{tabular}{|c|c|c|c|c|c|c|c|c|c|c|c|c|c|c|c|c|}
\hline \multirow[b]{2}{*}{ Test } & \multirow[b]{2}{*}{ Configuration } & \multirow[b]{2}{*}{$\begin{array}{l}\text { Load Cells } \\
\text { Force } \\
(\mathrm{N})\end{array}$} & \multicolumn{7}{|c|}{ Upper neck } & \multicolumn{7}{|c|}{ Lower neck } \\
\hline & & & $\begin{array}{l}+\mathrm{Fx} \\
(\mathrm{N})\end{array}$ & $\begin{array}{l}-\mathrm{Fx} \\
(\mathrm{N})\end{array}$ & $\begin{array}{l}\text { Fy (max) } \\
(\mathrm{N})\end{array}$ & $\begin{array}{l}-\mathrm{Fz} \\
(\mathrm{N})\end{array}$ & $\begin{array}{l}\text { Mx (max) } \\
(\mathrm{N} . \mathrm{m})\end{array}$ & $\begin{array}{l}+\mathrm{My} \\
\text { (N.m) }\end{array}$ & $\begin{array}{l}\text {-My } \\
\text { (N.m) }\end{array}$ & $\begin{array}{l}+\mathrm{Fx} \\
(\mathrm{N})\end{array}$ & $\begin{array}{l}-\mathrm{Fx} \\
(\mathrm{N})\end{array}$ & $\begin{array}{l}\text { Fy (max) } \\
(\mathrm{N})\end{array}$ & $\begin{array}{l}-\mathrm{Fz} \\
(\mathrm{N})\end{array}$ & $\begin{array}{l}\text { Mx (max) } \\
(\mathrm{N} . \mathrm{m})\end{array}$ & $\begin{array}{l}+\mathrm{My} \\
(\mathrm{N} . \mathrm{m})\end{array}$ & $\begin{array}{l}\text {-My } \\
\text { (N.m) }\end{array}$ \\
\hline 12 & $(-30,0)$ & 2998 & 602 & -146 & 45 & -2893 & 4.9 & 74.5 & 0.0 & 515 & -63 & 37 & -2791 & 3.2 & 114.6 & -25.8 \\
\hline 13 & $(-30,0)$ & 2887 & 632 & -154 & 43 & -2728 & 1.4 & 77.7 & 0.0 & 554 & -63 & 39 & -2643 & 3.8 & 109.7 & -26.5 \\
\hline $13 b$ & $(-30,0)$ & 2657 & 588 & -126 & 33 & -2469 & 1.7 & 70.6 & 0.0 & 531 & -59 & 37 & -2366 & 3.9 & 97.2 & -25.4 \\
\hline 9 & $(-15,0)$ & 4226 & 469 & -190 & 28 & -4141 & 3.4 & 62.8 & 0.0 & 375 & -156 & 28 & -3941 & 3.4 & 198.2 & -23.8 \\
\hline 10 & $(-15,0)$ & 3973 & 473 & -212 & 36 & -3846 & 1.4 & 72.6 & 0.0 & 469 & -136 & 37 & -3680 & 2.3 & 178.4 & -24.9 \\
\hline 22 & $(-15,0)^{\ddagger}$ & 10917 & 1239 & -367 & 49 & -9428 & 3.8 & 184.0 & 0.0 & 753 & -344 & 123 & -8438 & 4.7 & 463.5 & -38.9 \\
\hline 1 & $(0,0)$ & 4931 & 297 & -152 & 40 & -4941 & 8.5 & 15.7 & -19.3 & 56 & -321 & 96 & -4736 & 9.4 & 291.8 & -8.7 \\
\hline 6 & $(0,0)$ & 4267 & 291 & -228 & 45 & -4208 & 5.6 & 50.7 & 0.0 & 315 & -152 & 38 & -3978 & 6.5 & 213.2 & -27.8 \\
\hline $6 b$ & $(0,0)$ & 4336 & 299 & -216 & 82 & -4351 & 16.9 & 41.9 & 0.0 & 271 & -151 & 154 & -4121 & 16.5 & 222.6 & -27.9 \\
\hline 14 & $(0,0)^{*}$ & 5677 & 692 & -280 & 26 & -5257 & 4.8 & 115.1 & 0.0 & 661 & -251 & 85 & -5005 & 9.5 & 249.1 & -27.1 \\
\hline 15 & $(0,0)^{\dagger}$ & 9425 & 626 & -326 & 38 & -9284 & 14.7 & 35.9 & -10.4 & 0 & -330 & 81 & -8037 & 11.9 & 481.1 & -38.5 \\
\hline 7 & $(15,0)$ & 4231 & 71 & -180 & 21 & -4329 & 3.5 & 27.7 & -11.4 & 25 & -157 & 13 & -4031 & 3.3 & 262.7 & -3.7 \\
\hline 8 & $(15,0)$ & 4063 & 59 & -313 & 21 & -4005 & 2.1 & 32.5 & -20.0 & 46 & -187 & 26 & -3710 & 1.9 & 256.3 & 0.0 \\
\hline 19 & $(15,0)^{\dagger}$ & 6979 & 368 & -1158 & 335 & -6579 & 16.6 & 124.6 & -110.9 & 73 & -1189 & 169 & -6044 & 28.5 & 437.8 & 0.0 \\
\hline 11 & $(30,0)$ & 2989 & 2 & -979 & 125 & -2941 & 7.9 & 66.2 & -63.2 & 9 & -609 & 39 & -2682 & 13.1 & 239.7 & -0.2 \\
\hline 4 & $(30,0)$ & 2639 & 21 & -714 & 307 & -2597 & 24.9 & 77.0 & -62.1 & 72 & -588 & 93 & -2482 & 18.9 & 216.5 & -0.1 \\
\hline 20 & $(30,0)^{\dagger}$ & 6728 & 40 & -963 & 331 & -5971 & 27.1 & 89.5 & -116.7 & 5 & -993 & 130 & -5409 & 36.0 & 399.8 & 0.0 \\
\hline 21 & $(45,0)$ & 1887 & 49 & -551 & 105 & -1591 & 8.4 & 43.0 & -42.4 & 0 & -575 & 44 & -1435 & 12.3 & 148.5 & 0.0 \\
\hline 18 & $(-15,15)$ & 3637 & 423 & -139 & 392 & -3661 & 46.0 & 33.0 & 0.0 & 128 & -123 & 388 & -3476 & 47.7 & 179.5 & -18.2 \\
\hline 2 & $(0,15)$ & 4240 & 359 & -166 & 308 & -4294 & 43.7 & 20.9 & 0.0 & 76 & -143 & 329 & -4119 & 41.5 & 230.1 & -14.7 \\
\hline 16 & $(0,15)$ & 4011 & 310 & -199 & 329 & -4049 & 44.1 & 39.3 & 0.0 & 162 & -156 & 365 & -3836 & 42.6 & 211.4 & -20.9 \\
\hline 17 & $(15,15)$ & 3549 & 13 & -565 & 287 & -3570 & 35.9 & 59.9 & -48.0 & 0 & -530 & 258 & -3292 & 32.7 & 243.3 & 0.0 \\
\hline 3 & $(0,30)$ & 2731 & 349 & -80 & 501 & -2646 & 31.1 & 33.5 & 0.0 & 149 & -67 & 334 & -2587 & 53.9 & 130.8 & -6.2 \\
\hline $3 c$ & $(0,30)$ & 2504 & 278 & -137 & 454 & -2505 & 29.2 & 24.4 & 0.0 & 142 & -46 & 314 & -2401 & 49.6 & 128.6 & -13.3 \\
\hline 5 & $(0,30)^{\ddagger}$ & 7029 & 614 & -151 & 984 & -6180 & 99.9 & 27.1 & -3.1 & 141 & -155 & 649 & -5984 & 121.1 & 328.4 & -24.0 \\
\hline
\end{tabular}

* $1.93 \mathrm{~m} . \mathrm{s}^{-1}$ impact velocity; ${ }^{\dagger} 2.62 \mathrm{~m} . \mathrm{s}^{-1}$ impact velocity; ${ }^{\ddagger} 3.1 \mathrm{~m} . \mathrm{s}^{-1} \mathrm{~m} / \mathrm{s}$ impact velocity; $1.4 \mathrm{~m} . \mathrm{s}^{-1}$ impact velocity where unspecified 
Author Created Version

Original source of publication: Annals of Biomedical Engineering 37(7), p. 1403-1414, 2009

DOI: 10.1007/s10439-009-9711-4

The original publication is available at www.springerlink.com:

http://www.springerlink.com/openurl.asp?genre=article\&id=doi:10.1007/s10439-009-9711-4

TABLE 3. Nij.

\begin{tabular}{|c|c|c|c|c|c|c|c|}
\hline \multirow[b]{2}{*}{ Test } & \multirow[b]{2}{*}{ Configuration } & \multicolumn{3}{|c|}{ Upper neck } & \multicolumn{3}{|c|}{$\begin{array}{l}\text { Lower neck } \\
\text { (C7-T1) }\end{array}$} \\
\hline & & $\mathrm{N}_{\mathrm{CE}}$ & $\mathrm{N}_{\mathrm{CF}}$ & $\mathrm{N}_{\mathrm{ij}}$ & $\mathrm{N}_{\mathrm{CE}}$ & $\mathrm{N}_{\mathrm{CF}}$ & $\mathrm{N}_{\mathrm{ij}}$ \\
\hline 12 & $(-30,0)$ & 0 & 0.67 & 0.67 & 0 & 0.64 & 0.64 \\
\hline 13 & $(-30,0)$ & 0 & 0.64 & 0.64 & 0 & 0.60 & 0.60 \\
\hline $13 b$ & $(-30,0)$ & 0 & 0.58 & 0.58 & 0 & 0.54 & 0.54 \\
\hline 9 & $(-15,0)$ & 0 & 0.83 & 0.83 & 0 & 0.96 & 0.96 \\
\hline 10 & $(-15,0)$ & 0 & 0.82 & 0.82 & 0 & 0.88 & 0.88 \\
\hline 22 & $(-15,0)^{\ddagger}$ & 0 & 2.10 & 2.10 & 0 & 2.13 & 2.13 \\
\hline 1 & $(0,0)$ & 0.91 & 0.17 & 0.91 & 0 & 1.25 & 1.25 \\
\hline 6 & $(0,0)$ & 0 & 0.82 & 0.82 & 0 & 0.99 & 0.99 \\
\hline $6 b$ & $(0,0)$ & 0 & 0.82 & 0.82 & 0 & 1.03 & 1.03 \\
\hline 14 & $(0,0)^{*}$ & 0 & 1.19 & 1.19 & 0 & 1.22 & 1.22 \\
\hline 15 & $(0,0)^{\dagger}$ & 1.43 & 1.53 & 1.53 & 0 & 2.09 & 2.09 \\
\hline 7 & $(15,0)$ & 0.75 & 0.65 & 0.75 & 0 & 1.08 & 1.08 \\
\hline 8 & $(15,0)$ & 0.76 & 0.46 & 0.76 & 0 & 1.02 & 1.02 \\
\hline 19 & $(15,0)^{\dagger}$ & 1.72 & 0.38 & 1.72 & 0 & 1.65 & 1.65 \\
\hline 11 & $(30,0)$ & 0.92 & 0.23 & 0.92 & 0 & 0.81 & 0.81 \\
\hline 4 & $(30,0)$ & 0.85 & 0.24 & 0.85 & 0 & 0.73 & 0.73 \\
\hline 20 & $(30,0)^{\dagger}$ & 1.64 & 0.30 & 1.64 & 0 & 1.48 & 1.48 \\
\hline 21 & $(45,0)$ & 0.53 & 0.11 & 0.53 & 0 & 0.47 & 0.47 \\
\hline 18 & $(-15,15)$ & 0.12 & 0.68 & 0.68 & 0 & 0.86 & 0.86 \\
\hline 2 & $(0,15)$ & 0 & 0.75 & 0.75 & 0 & 1.05 & 1.05 \\
\hline 16 & $(0,15)$ & 0 & 0.77 & 0.77 & 0 & 0.98 & 0.98 \\
\hline 17 & $(15,15)$ & 0.88 & 0.22 & 0.88 & 0 & 0.93 & 0.93 \\
\hline 3 & $(0,30)$ & 0 & 0.51 & 0.51 & 0 & 0.64 & 0.64 \\
\hline 3c & $(0,30)$ & 0 & 0.47 & 0.47 & 0 & 0.60 & 0.60 \\
\hline 5 & $(0,30)^{\ddagger}$ & 0 & 1.07 & 1.07 & 0 & 1.51 & 1.51 \\
\hline
\end{tabular}

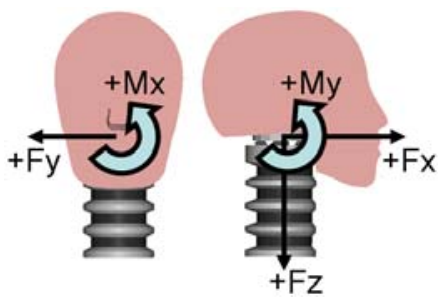

FIGURE 2. Sign convention for neck forces and moments (action of the neck on the head). +Fy is to the right in the head's local frame of reference. Convention is identical for action of the torso on the neck. 

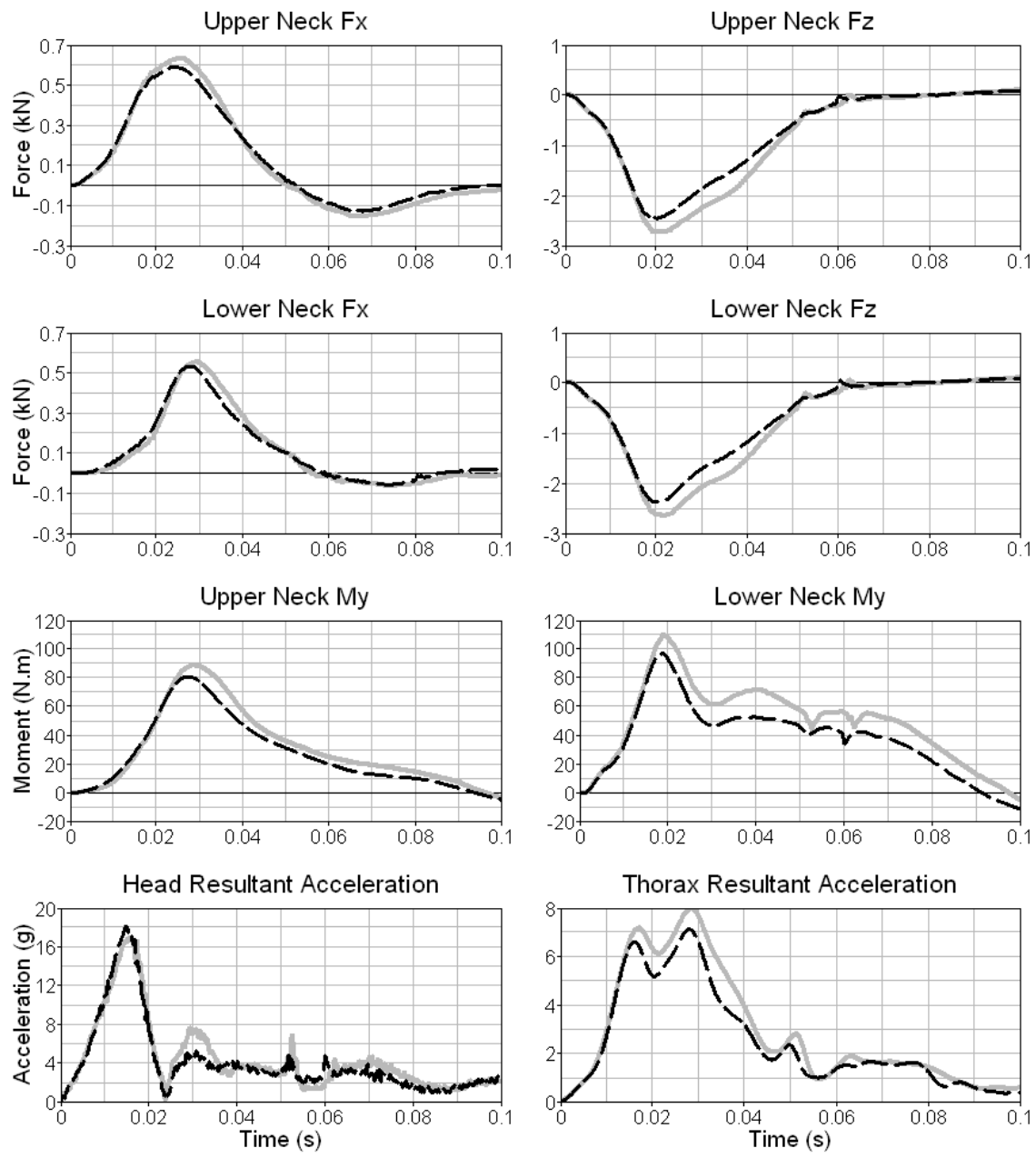

FIGURE 3. Compared time-histories for main relevant outputs, for tests 13 (grey line) and 13b (black dotted line), configuration $(-30,0)$.

\section{DISCUSSION}

Twenty six drop tests were performed using an inverted $50^{\text {th }}$ percentile male Hybrid III ATD at impact speeds and orientations selected to represent occupant loading in rollover crashes and historical cadaver test configurations. First, study limitations will be discussed.

\section{Drop-rig and test protocol}

Inverted drop-tests were chosen as a method to investigate the behaviour of the ATD in superior-inferior impacts. As opposed to eg. pendulum or impactor type protocols, this setup was chosen as its reference configuration replicated closely historical cadaveric drop-tests. In particular, any possible differences in the full dummy behaviour, its constraints, or in the effective masses involved in the impact, which could have resulted from using a horizontal setup, were expected to be minimised. An experimental setup was designed, that allowed the dummy to be in free fall at the moment of impact, while its configuration was controlled during guided free-drop.

At $1.4 \mathrm{~m} . \mathrm{s}^{-1}$, and for a given impact configuration $(-30,0)$, the drop rig operated to provide repeatable impacts. Due to the availability of the dummy and impact laboratory, it was not possible to include additional tests aimed specifically at assessing the repeatability of the test environment. In our test-series, the protocol used to position the dummy was the same for all tests. Moreover, the repeatability of the dummy head/neck/torso and of its measurements in axial impact conditions had been shown to be good in a previous study ${ }^{18}$. Even so, it is acknowledged that the potential remained for the repeatability to be degraded at higher drop-heights or for other configurations. 


\section{Author Created Version}

Original source of publication: Annals of Biomedical Engineering 37(7), p. 1403-1414, 2009

DOI: $10.1007 /$ s10439-009-9711-4

The original publication is available at www.springerlink.com:

http://www.springerlink.com/openurl.asp?genre=article\&id=doi:10.1007/s10439-009-9711-4

The impact velocity was achieved by a precise positioning of the dummy at a given drop-height. The estimated actual impact and target velocities were close. However, for the $1.4 \mathrm{~m}_{\mathrm{s}}{ }^{-1}$ tests it was estimated that the measurement error could potentially reach the same order of magnitude as the true difference between actual and target velocities due to camera resolution.

A factor that appeared more difficult to control was the actual impact angle, as compared to the target. The measured impact angles were all within five degrees of the target in the dummy's coronal plane and in most of the cases in its sagittal plane. In the five tests were this value was exceeded, slight movement of the dummy was apparent during the free fall, possibly due to a combination of rope tension relaxation and slip/stick effects within the dummy's joints. For this reason, one test (test 14) was excluded from the analysis. These differences are small, and inherent to the experimental protocol chosen, but it is acknowledged that the precise impact configuration influences the ATD's responses. Nevertheless, the analysis presented in the results section with regards to target impact configurations was still relevant, considering the fifteen degree interval chosen between each impact angle. To provide the opportunity to quantify the influence of impact orientation on ATD responses while accounting for these perturbations, the quantitative results were presented by taking into account and adding the relevant average perturbation plus one standard deviation to the intended impact angle (Figures 5 and 6). A similar correction can be applied to consider other outputs.

a)

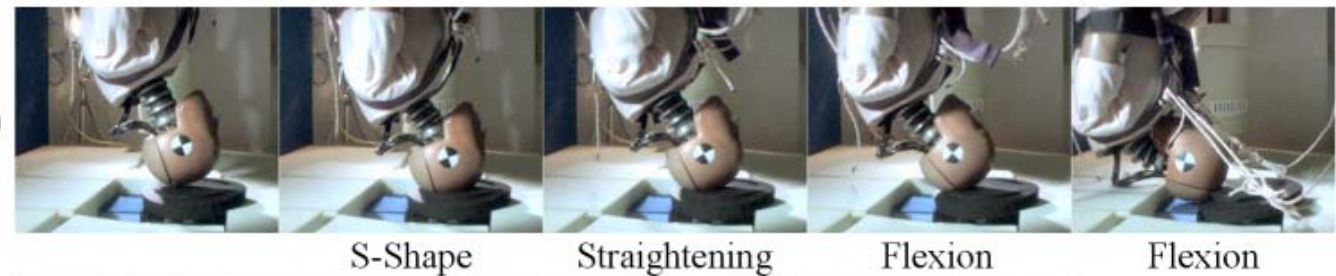

b)

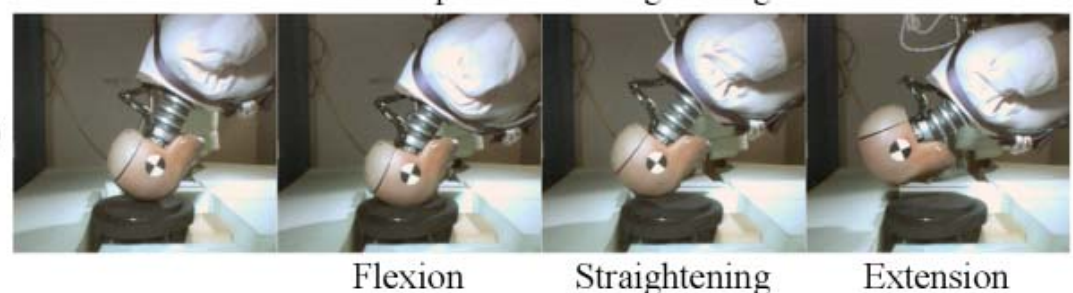

c)

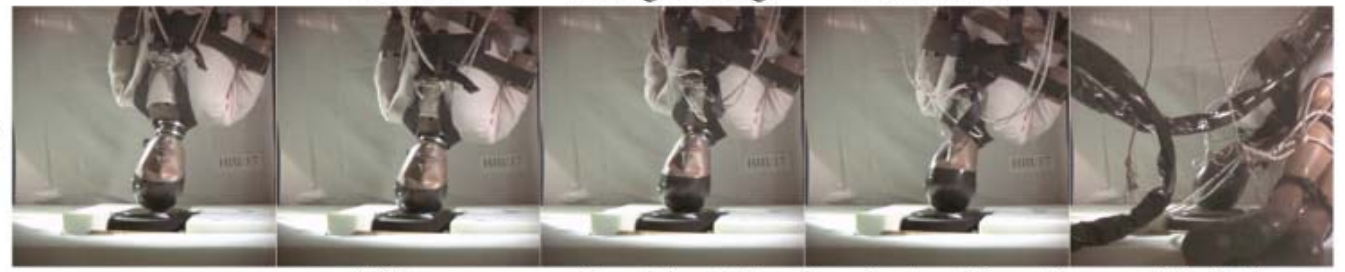

S-Shape (in both planes)

Combined Flexion, Lateral bending and Twisting

FIGURE 4. Comparison of ATD head/neck/thorax behaviours for configurations a) $(30,0)$, b) $(-30,0)$ and c) $(15,15)$ at 1.4 $\mathrm{m} . \mathrm{s}^{-1}$ impact velocity. Times at (0, 50, 100, 150 and 300 (a) / 485 (b) $\left.\mathrm{ms}\right)$.

\section{Comparison with the literature}

Peak impact and neck forces were compared to results from similar Hybrid III studies (Figure 7). The results from the $(0,0)$ configuration (Test 14 excluded) show a comparable trend line to published results with the same positioning of the dummy ${ }^{32,34}$. The average ratio between peak load cell force and lower neck axial force was $1.11 \pm 0.08$ for all tests. This compared well with the values reported by Pintar et al. or Sances et al. ${ }^{29,34}$ for the impact velocities considered in this study, and was consistent with an attenuation of the first, short duration part of the head/neck loading due to the padding ${ }^{31}$.

Some of the biofidelity issues of the Hybrid III have been presented and discussed before ${ }^{12}$, related to its high combined head/neck/torso stiffness. In a drop-test setup similar to our reference or $(15,0)$ configuration $^{10}$, a human volunteer's neck flexed, and its head escaped the torso loading path, whereas the Hybrid III neck did not. We observed that only in the ‘flexion' configurations was the Hybrid III able to exhibit such significant flexion. In these configurations, and to a 
lesser extent in the lateral configuration, the dummy also exhibited an initial s-shape phase where the torso was significantly stopped. A similar behaviour had been described in tests using full cadavers and cervical spine segments in axial loading $24,25,37$, or in FE simulations of head and neck in combined axial and lateral loading. When induced by constraining the head in rotation in cervical spine segments, it was associated with Bilateral Facet Dislocation at the lower cervical spine level ${ }^{23}$. However, the ATD did not exhibit the bi-modal behaviour sometimes observed in cadaveric segments ${ }^{24}$, as upper and lower neck force maxima occurred simultaneously, and did not present dynamic buckling or any higher order buckling shapes as reported by these authors.
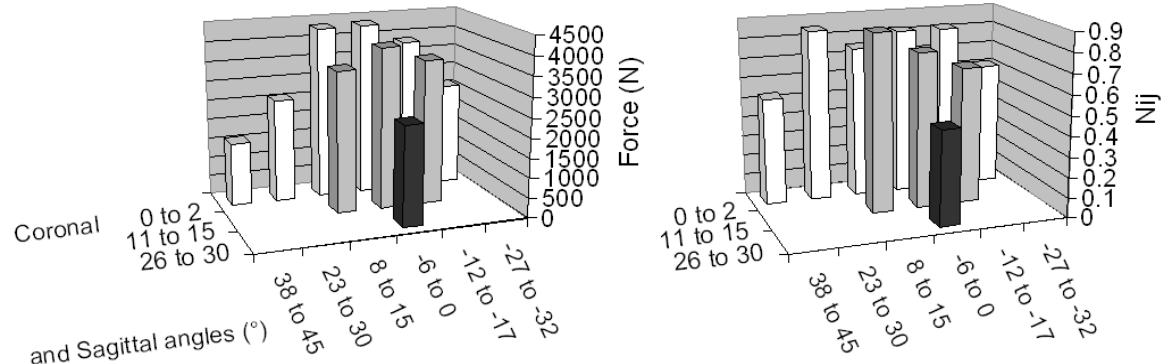

FIGURE 5. Distribution of: a) peak upper neck axial force and, b) $\mathrm{N}_{\mathrm{ij}}$ at $1.4 \mathrm{~m} . \mathrm{s}-1$ as a function of the impact configuration.
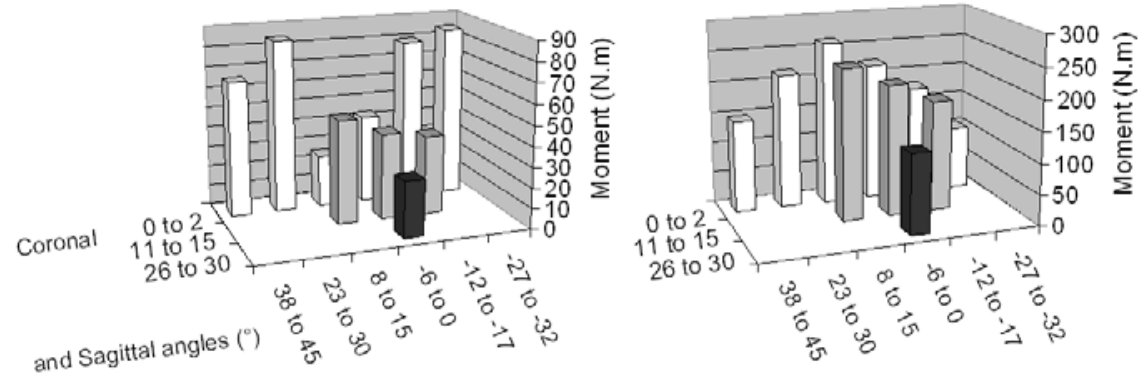

FIGURE 6. Distribution of: a) peak upper neck flexion moment and, b) peak lower neck flexion moment at $1.4 \mathrm{~m} . \mathrm{s}^{-1}$ as a function of the impact configuration.

Figure 8 presents the peak impact forces compared to results from similar configuration cadaveric drop-tests in the sagittal plane ${ }^{26,37}$. To draw this figure, each cadaveric impact force was normalized by the ratio between the ATD's and the cadaver bodyweight. The measured forces and predicted trends from the Hybrid III impacts are generally still higher than the impact forces obtained this way. The closest match between the Hybrid III and these cadaveric results was observed for the $(30,0)$ flexion configuration, with a test series where the authors had restrained each cadavers' head in an attempt to model the neck behaviour of a living subject ${ }^{37}$. It is expected that increasing the fixed flexion angle of the Hybrid III's lower neck plate would facilitate both a behaviour and a relative initial positioning of the head/neck/thorax that are closer to the volunteer/cadaveric behaviours described above. This may also improve the ability of the dummy to model the risk of hyperflexion ${ }^{31}$ by allowing the neck to flex earlier during the contact, and may reduce the stiff rebound observed in the extension impact configurations.

\section{Influence of the boundary conditions}

The comparison of tests performed with and without the PVC tape suggests that ATD neck forces and moments increase with the coefficient of friction. In these experiments differences were small and limited to cases where impact angles were high enough to induce significant friction loads.

The tests showed that the ATD's orientation at impact influenced both the dummy's responses and neck loads. Figure 5 summarises results from all tests with PVC at $1.4 \mathrm{~m} . \mathrm{s}^{-1}$ shows how an initial 30 degree angle in any direction from the reference resulted in a consistent, significant reduction of key parameters such as peak upper neck axial forces and $\mathrm{N}_{\mathrm{ij}}$. 


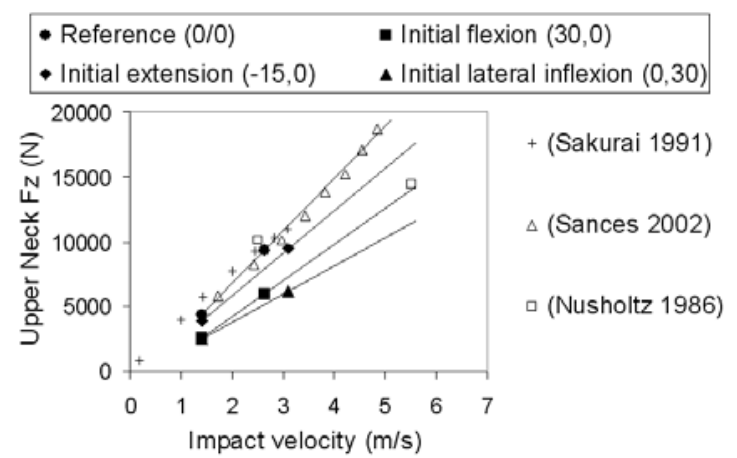

FIGURE 7. Comparison of the peak upper neck axial force with results from similar Hybrid III tests from the literature, for the different impact configurations.

The position of the legs was also observed to influence neck loads. In test 6 the upper neck axial force reached $4208 \mathrm{~N}$ compared to $4941 \mathrm{~N}$ in test 1, where the dummy's legs were raised to 25 degrees from the horizontal. One very obvious consequence of this positioning on the video was that the whole head/neck/torso complex stayed "balanced" and rebounded in a pure vertical movement when it hit the pad. In configurations 6 (or 6b), the legs continued with their downward movement as soon as the impact initiated. Due to the link and relative position of hip and pelvis joint, they directly transmitted the effect of their inertia to the torso as the impact continued. As a result, the dummy did not rebound purely vertically in these cases, and the effective mass contributing to the loading of the neck during the impact would have been less for tests 6/6b than for test 1 .

Both these observations are important, as they confirm that a relationship between neck axial load and impact velocity is only repeatable for a given effective mass and a given impact configuration.

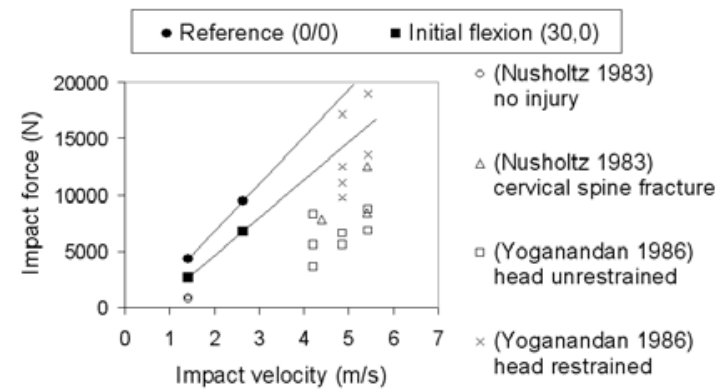

FIGURE 8. Comparison of the impact force from the HIII with results from similar cadaveric tests from the literature, for the impact configurations in the sagittal plane. The impact forces for the cadaver tests were normalised by body mass with reference to the HIII.

Coefficients of variation (CV) were calculated for each biomechanical parameter in all 1.4 m.s ${ }^{-1}$ impact tests within 30 degrees of the reference orientation. The CV analysis showed that some parameters were less sensitive than others to the impact angle. The resultant head acceleration, the $\mathrm{N}_{\mathrm{ij}}$ and the load cell force were the least sensitive to changes in impact orientation within these limits. However, the $\mathrm{N}_{\mathrm{CE}}$ and $\mathrm{N}_{\mathrm{CF}}$ were not correlated between neck levels and, in the flexion configurations, the $\mathrm{N}_{\mathrm{ij}}$ resulted from high upper neck extension moments. Therefore using the $\mathrm{N}_{\mathrm{ij}}$ may allow a reasonable estimate of the impact severity, in terms of its energy, regardless of the impact angle. However, the $\mathrm{N}_{\mathrm{ij}}$ may not be representative of the actual injury mechanism, such as BFDs associated with a local compression-flexion mechanism at the lower cervical level.

Finally, a ranking of all PVC tests' outputs at $1.4 \mathrm{~m} \cdot \mathrm{s}^{-1}$ suggests that multi-planar loadings of the dummy's head/neck complex, as obtained in configuration $(15,15)$, will result in the highest combined neck loads. This observation compares well with those of Nusholtz et al. ${ }^{26,27}$ who reported that low severity impacts could produce severe damage in out-of-position, asymmetrical (i.e. head rotated and flexed) impact configurations. It is also interesting to notice that the $\mathrm{N}_{\mathrm{ij}}$, in the contrary to the peak upper neck compressive force, appears to take the increased injury risk due to this configuration into account (see figure 5). 


\section{Author Created Version}

Original source of publication: Annals of Biomedical Engineering 37(7), p. 1403-1414, 2009

DOI: 10.1007/s10439-009-9711-4

The original publication is available at www.springerlink.com:

http://www.springerlink.com/openurl.asp?genre=article\&id=doi:10.1007/s10439-009-9711-4

\section{Considerations for neck injury risk assessment}

Experimental cadaveric studies ${ }^{1,25}, 30,39$ have shown that a small deviation of the applied load can have a significant influence on both the mechanism and severity of injury. A biofidelic ATD suitable for neck injury risk assessment should reflect the same response and sensitivity to boundary conditions as the human neck, and also be robust. To some extent, the Hybrid III is able to reproduce the compression-flexion behaviour observed in volunteers and cadavers, including both $1^{\text {st }}$ mode and $2^{\text {nd }}$ mode (s-shape) bending of the neck. It also appears to be sensitive to multi-planar loads.

In a given impact configuration, McElhaney et al. ${ }^{16}$ were able to link the impact velocity to the risk of cervical spine injury by reconstructing the boundary conditions associated with swimming pool injuries. Similarly, Mertz's et al.'s ${ }^{18}$ had reconstructed injurious events from American Football impact, which form the basis of the current neck injury criterion in compression (e.g. FMVSS208 Peak compression) of 4000N. Based on this and later work ${ }^{32,34}$, some attempts were made at linking the impact velocity to neck injury risk in inverted impacts ${ }^{22}$. Based on the observations presented in this paper, two different configurations could result in the same ATD upper neck axial force, but with different neck moments. Furthermore, in the case of rollover, two similar roof intrusion velocities may result in different forces and moments at neck level, depending on the relative positioning of the roof/dummy as well as the resulting orientation of the impact load. This observation is consistent with conclusions made by Viano et al. ${ }^{36}$ in a review of cadaveric tests in axial impact. Therefore roof intrusion velocity on its own may be difficult to link with neck injury risk through measurement of the ATD's neck compressive force alone, unless the impact configuration can be ascertained and utilised.

High levels of lower neck flexion moment were found, for configurations close to the vertical reference. At $2.62 \mathrm{~m} / \mathrm{s}$ the lower neck flexion moment Injury Assessment Reference Value (IARV) of 380 N.m proposed by Mertz et al. ${ }^{19}$ for the Mid Male ATD was exceeded for the $(0,0)$ configuration. These moments occurred roughly at the same time as the peak axial force at both levels. Although they may not be representative of the lower levels at injury reached in a human neck in flexion ${ }^{31}$, lower neck moments in combination with axial force (or the use of the $\mathrm{N}_{\mathrm{ij}(\mathrm{C} 7-\mathrm{T} 1 \text { ) }}$ ) appear relevant to injury mechanisms located at the lower levels of the cervical spine, especially since these injuries have also been described to be associated with the main force pulse at T1 level in cadaveric experiments ${ }^{24}$.

As for the lateral components measured in this study: the highest lateral shear force $(984 \mathrm{~N})$ was reached in the lateral $(0,30)$ configuration at $3.1 \mathrm{~m} \cdot \mathrm{s}^{-1}$. Although this exceeds proposed low level injury thresholds to volunteers ${ }^{15}$, it is lower than the severe injury IARV proposed by Mertz et al. ${ }^{19}$ at $3100 \mathrm{~N}$. The same observation can be made regarding the dummy's peak lower neck shear force. Lateral neck bending moment IARVs have been proposed for the BioSID, EuroSID and SID-HIII at $143 \mathrm{~N} . \mathrm{m}^{19}$ for the upper neck, and at 286 N.m for the lower neck. None of these levels was reached during these tests. It should be emphasised that these IARVs or injury thresholds are all assessed based on inertial loads, i.e. without head impact. Head impacts would exacerbate the injury risk and reduce the human neck injury tolerance level. In the light of the influence of out-of-the plane and combined loadings presented above, and as such lateral impact angles as 30 degrees can be expected in lateral rotation motion of the car associated with most rollovers, it appears that it would be important to include this assessment in the overall analysis of the neck injury risk. Because it is robust, reliable, and easily available, the Hybrid III ATD has been used so far in most attempts to perform rollover crashworthiness assessments. Using a dummy with an improved lateral head/neck/torso behaviour including in its coronal plane may provide a more reliable behaviour and measurements.

A neck injury criterion used in conjunction with the ATD should be able to model the risk associated with the main injury mechanisms. It is expected that the assessment of neck injury risk could be improved by including the lower neck flexion moment, and upper neck lateral flexion moment and shear forces, in combination with the upper neck axial force and flexion moment. However, at this stage, it appears that there is a crucial need for more data, either from experiments or from the real-life that would allow linking and correlating results from studies such as presented in this paper to experimental injury assessment. In particular, more information is needed on the specific influence of lateral angle and out-of-the-planes impacts on the risk of neck injury in compression.

To conclude, a reliable method was developed for testing ATD responses and biofidelity in rollover type impacts. The Hybrid III exhibited a first bending mode and a second s-shaped bending mode when it was dropped on its occiput. It rebounded without significant neck bending when dropped on its vertex or forehead. For a given impact velocity, all biomechanical parameters, including axial neck forces, measured during the drop-tests were significantly influenced by the impact orientation, including in particular lateral orientation. The $\mathrm{N}_{\mathrm{ij}}$ was sensitive to impact severity and less sensitive than other outputs to changes in orientation around a reference position. The combined use of the upper and lower neck moments provide opportunities to differentiate between loading modes and injury mechanisms. Further research is required to study these results in comparison to injury mechanisms and human tolerance limits. 


\section{Author Created Version}

Original source of publication: Annals of Biomedical Engineering 37(7), p. 1403-1414, 2009

DOI: 10.1007/s10439-009-9711-4

The original publication is available at www.springerlink.com:

http://www.springerlink.com/openurl.asp?genre=article\&id=doi:10.1007/s10439-009-9711-4

\section{ACKNOWLEDGEMENTS}

The authors would like to acknowledge the support of the Australian Research Council in funding this research via a Discovery Project (No. DP0663834), as well as the support of the New South Wales' Roads and Traffic Authority Crashlab for providing the calibrated dummy. In particular, the authors wish to thank Ross Dal Nevo, Colin Jackson and Malcolm Silva at the RTA Crashlab for their time and invaluable assistance, as well as Declan Patton and PaulAndré Pierré for their help during the tests.

\section{REFERENCES}

${ }^{1}$ Alem, N. M., G. S. Nuscholtz and J. Melvin. Head and neck response to axial impacts. 28th Stapp Car Crash Conference Paper No. 841667, 1984.

${ }^{2}$ Bahling, G. S., R. T. Bundorf, G. S. Kaspzyk, E. A. Moffatt, K. F. Orlowski and J. E. Stocke. Rollover and drop tests the influence of roof strength on injury mechanics using belted dummies. 34th Stapp Car Crash Conference Paper No. 902314, 1990.

${ }^{3}$ Benda, B., L. A. D'Aulerio, A. Cantor, M. Markushewski, B. Probst, L. A. Sicher and T. Sutherland. Performance of Automotive Seat Belts During Inverted (-Gz) Rollover Drop Tests. Proceedings of ICrash Conference, Athens Greece, July 4-7, 2006.

${ }^{4}$ Bidez, M., J. E. Cochran Jr, D. King and D. S. Burke III. Occupant dynamics in rollover crashes: influence of roof deformation and seat belt performance on probable spinal column injury. Annals of Biomedical Engineering 35:19731988, 2007.

${ }^{5}$ Bishop, P. J. and R. P. Wells. The Hybrid III anthropometric neck in the evaluation of head first collisions. SAE International Congress and Exhibition Paper No. 860201, 1986.

${ }^{6}$ Digges, K. H. Summary Report of Rollover Crashes. FHWA/NHTSA National Crash Analysis Centre. Available online:

http://foundationcenter.org/grantmaker/santos/rcsr.pdf:1-32, 2002.

${ }^{7}$ Eggers, A., F. Zhu, K. H. Yang and A. I. King. Predictions of neck load due to combined compression and lateral bending. International Journal of Vehicle Safety 1:118-128, 2005.

${ }^{8}$ Forrest, S., S. E. Meyer and B. Herbst. Head and neck injury potential in inverted impact tests. Proceedings of the 20th ESV Conference Paper No. 07-0371, 2007.

${ }^{9}$ Friedman, D., C. E. Nash and J. Bish. Observations from repeatable dynamic rollover tests. International Journal of Crashworthiness 12:67-76, 2007.

${ }^{10}$ Friedman, K., F. Gaston, J. Bish, D. Friedman and A. Sances Jr. An investigation of hybrid III and living human drop tests. Critical Reviews in Biomedical Engineering 28:219-223, 2000.

${ }^{11}$ Habberstad, J., R. Wagner and T. Thomas. Rollover and interior kinematics test procedures revisited. 30th Stapp Car Crash Conference Paper No. 861875, 1986.

${ }^{12}$ Herbst, B., S. Forrest, D. Chng and A. Sances Jr. Fidelity of anthropometric test dummy necks in rollover accidents, Proceedings of the 19th International Technical Conference on the Enhanced Safety of Vehicles Paper No. 98-S9-W-20, 1998.

${ }^{13}$ Heudorfer, B., M. Breuninger, U. Karlbauer, M. Kraft and J. Maidel. Roofbag - a concept study to provide enhanced protection for head and neck in case of rollover. Proceedings of the 19th Enhanced Safety of Vehicles Conference Paper No. 05-0398, 2005.

${ }^{14} \mathrm{Hu}$, J., J. B. Lee, K. H. Yang and A. I. King. Injury patterns and sources of non-ejected occupants in trip-over crashes: a survey of NASS-CDS database from 1997 to 2002. 49th annual proceedings of the Association for the Advancement of Automotive Medicine, 2005.

${ }^{15}$ Lund, A. Recommended procedures for evaluating occupant injury risk from deploying side airbags. Side Airbag OutOf-Position. Injury Technical Working Group, IIHS. First Revision - July 2003:1-45, 2003.

${ }^{16}$ McElhaney, J. H., R. G. Snyder, J. D. States and M. A. Gabrielson. Biomechanical Analysis of Swimming Pool Injuries. 23rd Stapp Car Crash Conference Paper No. 790137, 1979.

${ }^{17}$ McElhaney, J. H., B. Doherty, J. Paver, B. Myers and L. Grey. Combined bending and axial loading responses of the human cervical spine. 32nd Stapp Car Crash Conference Paper No. 881709, 1988.

${ }^{18}$ Mertz, H. J., V. Hodgson, M. Thomas and G. Nyquist. An Assessment of Compressive Neck Loads Under InjuryProducing Conditions. The Physician and Sportsmedicine 6(11):495-503, 1978.

${ }^{19}$ Mertz, H. J. and e. al. Biomechanical and scaling bases for frontal and side impact injury assessment reference values. Stapp Car Crash Journal 47:155-188, 2003.

${ }^{20}$ Moffatt, E. A., E. R. Cooper, J. J. Croteau, K. F. Orlowski, D. R. Marth and J. W. Carter. Matched-pair rollover impacts of rollcaged and production roof cars using the controlled rollover impact system (CRIS). SAE technical paper series Paper No. 2003-01-0172, 2003. 


\section{Author Created Version}

Original source of publication: Annals of Biomedical Engineering 37(7), p. 1403-1414, 2009

DOI: 10.1007/s10439-009-9711-4

The original publication is available at www.springerlink.com:

http://www.springerlink.com/openurl.asp?genre=article\&id=doi:10.1007/s10439-009-9711-4

${ }^{21}$ Myers, B. S. and B. A. Winkelstein. Epidemiology, classification, mechanism, and tolerance of human cervical spine injuries. Critical Reviews in Biomedical Engineering 23:307-409, 1995.

${ }^{22}$ Nash, C. E. and D. Friedman. A rollover human/dummy head/neck injury criteria. Proceedings of the 20th ESV conference Paper No. 07-0357, 2007.

${ }^{23}$ Nightingale, R., B. Myers, J. McElhaney, B. Doherty and W. Richardson. The influence of end condition on human cervical spine injury mechanisms. 35th Stapp Car Crash Conference Paper No. 912915, 1991.

${ }^{24}$ Nightingale, R. W., J. H. McElhaney, W. J. Richardson and B. S. Myers. Dynamic responses of the head and cervical spine to axial impact loading. Journal of Biomechanics 29:307-318, 1996.

${ }^{25}$ Nusholtz, G. S., J. W. Melvin, D. F. Huelke, N. M. Alem and J. G. Blank. Response of the Cervical Spine to SuperiorInferior Head Impact. 25th Stapp Car Crash Conference Paper No. 811005, 1981.

${ }^{26}$ Nusholtz, G. S., D. F. Huelke, P. Lux, N. M. Alem and F. Montalvo. Cervical Spine Injury Mechanism. 27th Stapp Car Crash Conference Paper No. 831616, 1983.

${ }^{27}$ Nusholtz, G. S. and P. S. Kaiker. Kinematics of the human cadaver spine in response to superior inferior loading of the head. GM crown head impact - neck. Final report. University of Michigan, Transportation Research Institute, Biosciences division. Ann Arbor, MI, USA. Final Report No. UMTRI-86-31, July 1-1986:116 pp., 1986.

${ }^{28}$ O'Brien-Mitchell, B. M., S. J. Cassatta, M. A. Giason, R. C. Lange and A. G. Melocchi. Data analysis methodology and observations from rollover sensor development tests. Proceedings of the 20th ESV Conference Paper No. 07-0308, 2007.

${ }^{29}$ Pintar, F. A., A. Sances Jr, N. Yoganandan, J. Reinartz, D. J. Maiman, J. K. Suh, G. Unger, J. F. Cusick and S. J. Larson. Biodynamics of the total human cadaveric cervical spine. 34th Stapp Car Crash Conference Paper No. 902309, 1990.

${ }^{30}$ Pintar, F. A., N. Yoganandan, L. Voo, J. Cusick, D. Maiman and A. Sances. Dynamic characteristics of the human cervical spine. 39th Stapp Car Crash Conference Paper No. 952722, 1995.

${ }^{31}$ Pintar, F. A., L. Voo, N. Yoganandan, T. H. Cho and D. Maiman. Mechanisms of Hyperflexion Cervical Spine Injury. Proceedings of the IRCOBI Conference:249-260, 1998.

${ }^{32}$ Sakurai, T., Y. Takigawa and H. Ikeno. Study on Passenger Car Rollover Simulation. Proceedings of the 13th International Technical Conference on Experimental Safety Vehicle Paper No. 91-S6-O-10, 1991.

${ }^{33}$ Sances Jr, A. (1998) Dynamic Comparison of the Hybrid III and Human Neck. In: Yoganandan N (ed) Frontiers in Head and Neck Trauma. IOS Press, pp 147-150.

${ }^{34}$ Sances Jr, A., F. Carlin and S. Kumaresan. Biomechanical analysis of head-neck force in hybrid III dummy during inverted vertical drops. Biomedical Sciences Instrumentation 38:459-464, 2002.

${ }^{35}$ Sances Jr, A., S. Kumaresan, R. Clarke, B. Herbst and S. Meyer. Biomechanical analysis of occupant kinematics in rollover motor vehicle accidents: Dynamic spit test. Biomedical Sciences Instrumentation 41:104-109, 2005.

${ }^{36}$ Viano, D. C. and C. Parenteau. Analysis of head impacts causing neck compression injury. Traffic Injury Prevention 9:144-152, 2008.

${ }^{37}$ Yoganandan, N., A. Sances, D. J. Maiman, J. B. Myklebust, P. Pech and S. J. Larson. Experimental spinal injuries with vertical impact. Spine 11:855-860, 1986.

${ }^{38}$ Yoganandan, N., M. Haffner, D. Maiman, H. Nichols, F. Pintar, J. Jentzen, S. Weinshel, S. Larson and A. Sances. Epidemiology and Injury Biomechanics of Motor Vehicle Related Trauma to the Human Spine. 33rd Stapp Car Crash Conference Paper No. 892438, 1989.

${ }^{39}$ Yoganandan, N., A. Sances, Jr. and F. Pintar. Biomechanical evaluation of the axial compressive responses of the human cadaveric and manikin necks. Journal of Biomechanical Engineering 111:250-255, 1989. 